\title{
Fetal exposure to arsenic results in hyperglycemia, hypercholesterolemia, and nonalcoholic fatty liver disease in adult mice
}

\author{
Pablo Sanchez-Soria ${ }^{1,5}$, Derrick Broka1', Stephanie Quach', Rhiannon N. Hardwick', Nathan J. Cherrington ${ }^{1,2}$ and Todd D. Camenisch ${ }^{1,2,3,4^{*}}$ \\ *Correspondence: camenisch@pharmacy.arizona.edu

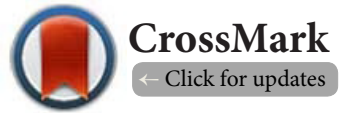 \\ 'Pharmacology and Toxicology, College of Pharmacy, University of Arizona, 1703 E. Mabel Street, 85721. Tucson, AZ, USA. \\ ${ }^{2}$ Steele Children's Research Center, University of Arizona, Tucson, AZ, USA. \\ ${ }^{3}$ Southwest Environmental Health Sciences Center, University of Arizona, Tucson, AZ, USA. \\ ${ }^{4} \mathrm{BIO} 5$ Institute, University of Arizona, Tucson, AZ, USA. \\ ${ }^{5}$ Center for Toxicology and Environmental Health, L.L.C., North Little Rock, AR, USA.
}

\begin{abstract}
Background: Exposure to arsenic is a major concern in the United States and worldwide, since this metalloid has been associated with a number of ailments, including cardiovascular and metabolic diseases. Environmental exposures to toxicants throughout fetal development have been shown to play a critical role as triggers of adult disease.

Methods: This study aimed to evaluate the contribution of fetal arsenic exposure to the onset of metabolic syndrome. Swiss Webster mice were exposed to either $100 \mathrm{ppb}$ sodium arsenite or sodium chloride via the dam's drinking water from embryonic day 6 until birth. Weight and metabolic end-points were evaluated throughout the 36 week study. Retroorbital bleeds and blood plasma analyses were done to evaluate glucose, lipids, triglycerides and liver enzymes. Livers were evaluated histologically to assess extent and progression of nonalcoholic fatty liver disease. Cardiovascular outcomes such as blood pressure and ventricular hypertrophy were evaluated using non-invasive tail-cuff method and echocardiography respectively.

Results: Blood plasma analysis demonstrated that in-utero (IU) arsenic-exposed mice exhibited a significant increase in plasma glucose levels between weaning age and 4 months of age, which remained elevated after 8 months. Similarly, IU arsenic-exposed mice showed a consistent elevation in LDL and total cholesterol at weaning age, 4 months and 8 months of age. Mouse weight was not statistically different between groups, and no significant cardiovascular changes were seen. Further histological analysis of liver samples demonstrated the development of nonalcoholic fatty liver disease in IU arsenic-exposed mice, as evidenced by major morphological changes and an increase in steatosis concomitant with hepatocellular ballooning.

Conclusions: Taken together, the results found in this study suggest that IU arsenic exposure is a possible contributor to metabolic syndrome onset in mice, having important implications in the evaluation of fetal exposures on the development of adult disease.
\end{abstract}

Keywords: Arsenic, metabolic, fetal, hypercholesterolemia, hyperglycemia, NAFLD

\section{Introduction}

Exposure to environmental arsenic is a major concern in the United States and worldwide. It is estimated that hundreds of millions of people are exposed to arsenic through drinking water on a daily basis [1]. The highest concentrations seen in drinking water are found in the endemic Blackfoot disease regions of Taiwan where mean concentrations of arsenic in water are around $700 \mu \mathrm{g} / \mathrm{L}$. Affected countries include Bangladesh, with over 30 million people exposed to concentrations between 0.1 $\mu \mathrm{g} / \mathrm{L}$ and $864 \mu \mathrm{g} / \mathrm{L}$, India, with 40 million people exposed to concentrations exceeding $1000 \mu \mathrm{g} / \mathrm{L}$, as well as China (1.5 million people) and the United States ( 2.5 million people) exposed to concentrations between $1 \mu \mathrm{g} / \mathrm{L}$ and $100 \mu \mathrm{g} / \mathrm{L}$ of arsenic in the drinking water [2-5]. Importantly, exposure to arsenic has been associated with an array of diseases ranging from multiple forms of cancer, to developmental and reproductive effects, as well as cardiovascular and metabolic disorders [6-9].

Early life exposures to environmental toxicants such as arsenic have been shown to be strong influential factors in triggering the etiology of certain cancers [10], yet such exposures have not been as clearly established as contributors to cardiovascular disease or metabolic disorders. Several studies indicate that in utero (IU) and early life exposure to environmental toxicants play a critical role in increasing susceptibility to chronic ailments including metabolic dysregulation and cardiovascular disease [10-13]. A study performed by Yuan et al., in the region II of Chile provided key evidence supporting the idea that fetal exposure to arsenic is a strong contributor to increased cardiovascular mortality. Importantly, this region of Chile provided a unique opportunity to evaluate long-term health effects of early 
Sanchez-Soria et al. Journal of Toxicology and Health 2014,

http://www.hoajonline.com/journals/pdf/2056-3779-1-1.pdf

doi: 10.7243/2056-3779-1-1

exposures to arsenic, since the period of high exposure was well defined by a sharp reduction of arsenic in municipal water. The study by Yuan et al., evaluated cardiovascular mortality ratios between 1950 and 2000, and demonstrated that young adults aged 30-49 who were born during the high exposure period with exposure IU and throughout early childhood, had the highest myocardial infarction mortality rates. These findings suggest that early exposure to arsenic promotes the development of cardiovascular disease throughout adulthood [10]. Similarly, multiple studies have shown that stress during pregnancy (such as those from exposures to environmental contaminants), and low birth weight during infancy are associated with an increased risk of coronary heart disease, hypertension, type 2 diabetes, and the development of metabolic syndrome in adulthood [14-18] Additionally, Wang et al., show a linear relationship between arsenic content in hair (as a marker of exposure) and increased plasma glucose and lipids, as well as elevated blood pressure, associating arsenic exposure to an increased prevalence of metabolic syndrome [19]. Similarly, a recent study performed in South Korea showed that hair samples from patients with metabolic syndrome had significantly elevated arsenic content when compared with patients not diagnosed with metabolic syndrome [20].

Although metabolic syndrome is often classified as a disease, it is rather best described as a cluster of risk factors that together contribute to decreased cardiovascular and metabolic health. Metabolic syndrome is defined by the presence of 3 or more of the following risk factors: 1) Elevated waist circumference (men >40"; women $>35^{\prime \prime}$ ); 2 ) Elevated triglycerides (>150 $\mathrm{mg} / \mathrm{dl}) ; 3)$ reduced high density lipoprotein $(\mathrm{HDL})(<40 \mathrm{mg} /$ dl); 4) elevated blood pressure $(>130 / 85 \mathrm{mmHg}) ; 5$ ) elevated fasting glucose $(>100 \mathrm{mg} / \mathrm{dl})[\mathbf{2 1}, \mathbf{2 2}]$. Furthermore, steatosis-a process of lipid accumulation within liver cells-often leads to the development of nonalcoholic fatty liver disease (NAFLD), a hepatic manifestation of metabolic syndrome [23]. While steatosis is not a risk factor considered in the diagnosis of metabolic syndrome, it is often an important influence in the progression of this disease, negatively impacting liver function.

Metabolic syndrome has become a major public health concern and is a major cause of morbidity and mortality worldwide. It is estimated that the prevalence of metabolic syndrome among the general population is between 17 and 25\% [24]. Additional reports within the United States suggest an even higher percent for the American population, at around 34\% [25]. Various studies indicate that the major contributors to metabolic syndrome are insulin resistance, obesity and genetic predisposition; however, little is known about the contribution of environmental factors (such as arsenic exposure). Upon evaluating systemic effects of arsenic, it has been noted that oxidative stress contributes to the progression of diabetic vascular complications. While several studies support the hypothesis that arsenic exposure increases risk of type 2 diabetes, a lack in consensus exists due to experimental design limitations, making it difficult to evaluate a causal link [26]. Nevertheless, increasing biochemical data tend to strengthen this link between arsenic exposure and metabolic dysregulation [27-29]. Clearly, metabolic dysregulation is a complex, multifactorial condition that requires the evaluation of how each factor may contribute, including the effects of early-life exposures to environmental contaminants and how they may predispose or contribute to disease onset.

Cardiovascular and metabolic diseases develop as a result of complex interactions between genetic predisposition and lifestyle, including interactions with the surrounding environment both during development and throughout life. Despite increased awareness of the benefits of a healthier lifestyle, greater emphasis on diet and substantial improvement in pharmaceutical treatments, cardiovascular pathologies remain the leading cause of death. This suggests there still remains a significant gap in our understanding of contributing factors underlying cardiovascular disease and metabolic syndrome. As a basis for this study, we hypothesized that arsenic exposure during fetal development contributes to the onset and progression of metabolic disorders known to be risk factors for cardiovascular health. In order to assess this, we aimed to understand the metabolic outcomes resulting from fetal exposure to arsenic by evaluating biochemical, as well as physiological and histological markers of disease.

\section{Methods}

\section{Animals and treatments}

Swiss Webster pregnant mice were purchased from Harlan (Harlan Laboratories Inc, WI, USA). Treatment groups were initiated at embryonic day 6 (E6) by exposing the dams to either 100 parts per billion (ppb) sodium arsenite $\left(\mathrm{NaAsO}_{2}\right.$ Sigma, St. Louis, MO, USA) or 100 ppb sodium chloride ( $\mathrm{NaCl}$ VWR, Aurora, CO, USA) through drinking water, and were maintained on their respective treatments until birth. Mice were housed in sterile microisolator cages and provided diet (2019 Teklad Global 19\% Protein Extruded Rodent Diet, Harlan Laboratories Inc, WI, USA) and water ad libitum. Offspring from arsenic exposed dams $(n=2)$ consisted of 3 females and 7 males $(n=10)$, whereas offspring from control dams $(n=2)$ consisted of 8 females and 2 males $(n=10)$. At weaning age (day 21), mice were separated by treatment and gender.

Systolic and diastolic blood pressures were measured biweekly using a volume pressure tail cuff transducer system coupled to computerized data acquisition software as previously described [9]. Mouse weights were recorded prior to acclimation to blood pressure analysis. Transthoracic echocardiography was performed on anesthetized animals at 2 and 6 months of age to assess left ventricular hypertrophy as described [9].

Blood samples were collected at weaning age, 4 months, and 8 months of age by retro-orbital puncture under a running laminar flow hood and sterile conditions. Approximately $250-$ $300 \mu \mathrm{L}$ of blood were collected from non-fasted mice between 12:00 PM and 1:00 PM. Autoclaved capillary tubes were used 
for puncture and collection of blood into eppendorf tubes containing $7 \mu \mathrm{L}$ of heparin. Blood plasma was obtained by centrifugation, frozen in liquid nitrogen, and subsequently stored at $-80^{\circ} \mathrm{C}$ until analysis. Mice were euthanized by $\mathrm{CO}_{2}$ asphyxiation and cervical dislocation. Organs were harvested and processed for histology. All animal use and experimental protocols followed University of Arizona Institutional Animal Care and Use Committee (IACUC) regulations and remained in accordance with institutional guidelines.

\section{Plasma biochemistry analysis}

All plasma biochemical analyses were performed using the Diagnostics COBAS INTEGRA 400 Plus (Roche Diagnostics, Indianapolis, Indiana) by the Comparative Pathology Lab at University of California, Davis.

Glucose-Enzymatic reaction with hexokinase was performed, catalyzing the phosphorylation of glucose to glucose 6-phosphate (G6P), which is further oxidized by G6P dehydrogenase, leading to the production of NADPH. NADPH formation is directly proportional to the glucose concentration, and was measured by the increase in absorbance at $340 \mathrm{~nm}$.

Cholesterol-Enzymatic cleavage by cholesterol esterase and further oxidation by cholesterol oxidase were performed, resulting in the production of hydrogen peroxide and cholest-4-en-3-one. Hydrogen peroxide combined with 4-aminoantipyrine and phenol, results in the production of a red dye detectable at an absorbance of $512 \mathrm{~nm}$. The color intensity was used to assess plasma cholesterol concentration. High Density Lipoprotein (HDL) and Low Density Lipoprotein $(L D L)$-Homogeneous enzymatic colorimetric assays were performed by selective solubilization of HDL and LDL through the removal of unwanted lipid fractions. HDL cholesterol was analyzed by the addition of magnesium and dextran sulfate prior to polyethylene glycol-modified enzyme addition for hydrolysis. LDL cholesterol was solubilized by the addition of a nonionic detergent and a sugar compound. Addition of a sugar compound allows for the selective determination of LDL cholesterol as hydrolysis by cholesterol esterases occurs. $\mathrm{HDL}$ and LDL cholesterol were determined after selective solubilization by the addition of a dye reacting with hydrogen peroxide (as described in cholesterol subsection (see above)), and absorbance intensity was measured at $585 \mathrm{~nm}$.

Triglycerides-Free glycerol was removed from plasma samples prior to enzymatic hydrolysis of triglycerides. Liberated glycerol after hydrolysis by lipase was quantified in a colorimetric reaction by the phosphorylation of glycerol to glycerol-3-phosphate, and further oxidation to produce hydrogen peroxide, reacting with 4-aminophenazone, and 4-chlorophenol. This oxidation product leads to a change in color directly proportional to the amount of triglycerides in the sample.

Liver enzymes-Enzymatic activity based assays were used to colorimetrically measure liver enzyme concentrations in plasma samples.
Alanine Transaminase (ALT) levels were calculated by reacting the sample with L-Alanine +2 -oxoglutarate, leading to the production of pyruvate, and reacted with lactate dehydrogenase in excess of NADH. This reaction leads to the production of $\mathrm{NAD}^{+}$and a decrease in $\mathrm{NADH}$, which can be measured at $340 \mathrm{~nm}$, and is directly proportional to the amount of ALT.

Aspartate Transaminase (AST) is measured in a similar fashion to ALT, by reacting L-aspartate +2 -oxoglutarate with the plasma sample, and then using malate dehydrogenase in the excess of $\mathrm{NADH}$, to produce $\mathrm{NAD}^{+}$and measure the decrease in absorbance of NADH.

Alkaline Phosphatase (ALP) is measured by reacting $p$-nitrophenyl phosphate with the plasma sample to produce phosphate $+p$-nitrophenol, which is measured at an absorbance of $409 \mathrm{~nm}$.

\section{Histology}

All organs were harvested and rinsed in phosphate buffered solution (PBS) (Mediatech, Herndon, VA, USA). Liver sections used for Hematoxylin \& Eosin (H\&E) and Masson's trichrome stains were rinsed in PBS, and fixed in $4 \%$ paraformaldehyde (Fisher, Fair Lawn, NJ, USA) at $4^{\circ} \mathrm{C}$ overnight. Fixed tissue was embedded in Paraplast $56^{\circ} \mathrm{C}$ (McCormick Scientific, St. Louis, $\mathrm{MO}$, USA), and sectioned in the transverse plane into $10 \mu \mathrm{m}$ sections using a microtome (HM 325 Microtom, Thermo Scientific, Waltham, MA, USA). Additional tissue samples were embedded in Tissue-Tek OCT compound and snap frozen in liquid nitrogen for cryo-sectioning and Oil Red-O stain for lipid content analysis. Histology was documented using a DFC320 camera linked to a DM 2500 microscope (Leica Microsystems). The histological features of steatosis, fibrosis, inflammation and hepatocellular ballooning were semi-quantitatively evaluated in H\&E and Masson's trichrome stains through the (NAFLD) activity scoring (NAS) system as described [30]. Four liver sections were analyzed per mouse liver.

\section{Statistical analyses}

Mouse weights were averaged by gender and treatment groups, and analyzed using repeated measures analysis of variance (RM-ANOVA). Terminal liver enzymes (ALT, AST, and ALP) were averaged by treatment group and statistical significance was determined by the Student's T-test. Blood plasma biochemistries were analyzed using a linear mixed effects model. This modeling procedure extends the usual linear model by including, in addition to fixed effects, random effects that account for correlations among observations in the data. In this case, mice were measured repeatedly over time and we attempted to capture the covariance structure of these dependent observations by modeling the withinmouse correlations. Specifically, we modeled the natural log concentrations of the blood biochemistry analytes with fixed effects including gender, treatment group, and time, as well as the interactions between them. The random effects included a unique intercept and time-associated slope for 
each mouse, where each random component was assumed to come from a normal distribution with mean zero and constant variance. While graphical data representation for blood biochemistry analytes in Figures $\mathbf{2}$ and $\mathbf{3}$ are shown as a combination of male and female values, the statistical analysis and statistical significance are a result of mixed effects model analysis, not the combined gender averages.

\section{Results}

\section{Body weight changes}

Given the associations between cardiovascular, metabolic disorders and obesity, we evaluated growth changes during the 36 week period after birth. Female pups exposed to arsenic showed a statistically significant decrease in weight at two weeks of age, when compared to control females $(p<0.05)$ (Figure 1A). While this difference in weight was apparent at 2 weeks of age, female mice recovered quickly, and by 4 weeks of age, there was no difference between IU arsenic-exposed and control mice (Figures $\mathbf{1 A}$ and $1 \mathrm{~B}$ ).
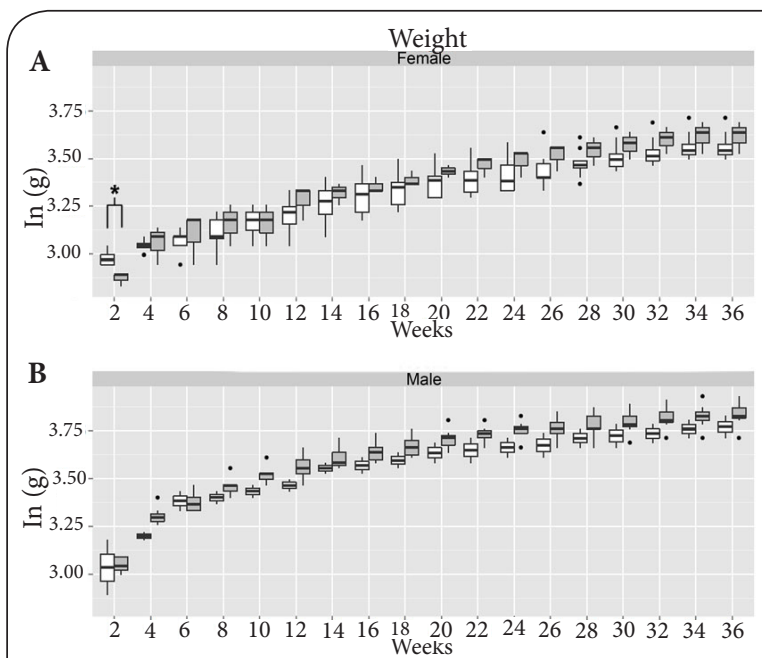

Figure 1. In utero arsenic exposure alters body weight during weaning age in female mice.

(A) Average weights were graphed over time between IU arsenic exposed (gray boxes) and control mice (white boxes). Weights were separated by gender showing females on top (B) and males on the bottom. Outliers are represented as dots. Statistical significance was found in the female group at 2 weeks of age $\left({ }^{*} \mathrm{p}<0.05\right)$.

\section{Blood plasma biochemistry}

Epidemiological reports show that populations exposed to arsenic through drinking water have an increased prevalence of type 2 diabetes mellitus and cardiovascular disease [26,31-33]. Our study demonstrates that blood glucose levels did not significantly change over time in control mice (Figure 2A). In contrast, IU arsenic-exposed mice had a significant increase over time in blood glucose ( $46 \%$ increase) $(p<0.01)$, as evidenced by a $39 \%$ increase between weaning age and 4 months $(p=0.05)$, and an additional $7 \%$ increase between 4 months and 8 months of age $(p=0.9)$ Further analysis of glucose levels in individual mice showed that control mice retained normoglycemic levels throughout the study (Figure 2B). The IU arsenic-exposed mice became hyperglycemic over time, and showed greater interindividual variability, as well as variability across the treatment group when compared to controls, strongly suggesting dysregulation of glucose homeostasis (Figure 2C). Given our previous findings on arsenic-related cardiovascular

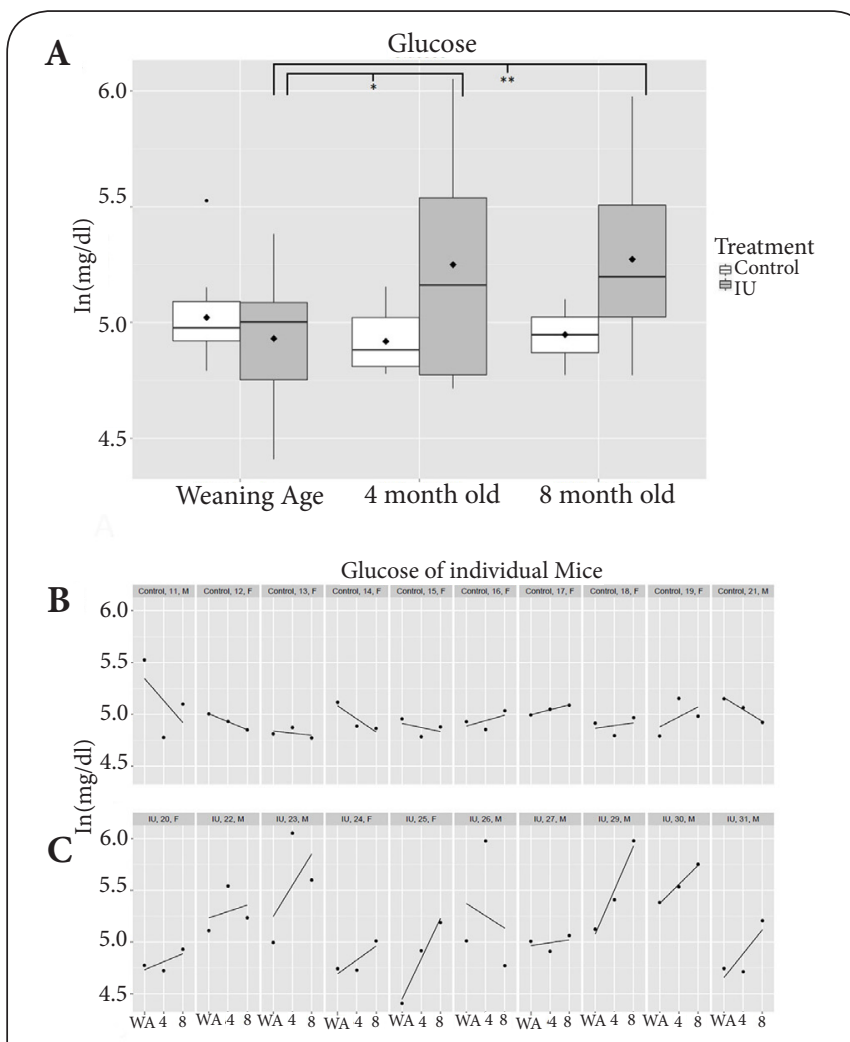

Figure 2. In utero arsenic exposure promotes hyperglycemia.

(A) In utero arsenic exposure increases blood plasma glucose. Blood plasma glucose from control (white boxes) and IU arsenic-exposed (gray boxes) mice was evaluated at the indicated time points. Box and whisker plots are shown for each time point. Sample means are represented by black diamonds. A significant increase between weaning age and 4 months of age was observed in the IU arsenic-exposed group $\left({ }^{*} \mathrm{p}<0.05\right)$, reaching greater significance by 8 months of age $\left({ }^{* *} \mathrm{p}<0.01\right)$.

$(\mathrm{B}, \mathrm{C})$ In utero arsenic exposure alters glucose homeostasis (B) Individual mouse glucose changes over time for control group, (C) show steady glucose values, whereas IU arsenicexposed mice. demonstrate a substantial variation within mouse measurements, as well as across treatment group. WA, weaning age; 4,4 months of age; 8,8 months of age; M, male; F, female.

pathologies [9], we evaluated cardiovascular outcomes as well as blood lipid profiles of these mice. While no significant 
cardiac remodeling, or changes in systolic or diastolic blood pressures were observed between treatment groups (data not shown), a striking increase in circulating cholesterol was detected. The IU arsenic-exposed group was $26 \%, 44 \%$ and $42 \%$ higher than the control group at weaning age $(p=0.08)$, 4 months ( $p=0.003)$ and 8 months $(p=0.002)$ respectively. Further analysis of variation within groups demonstrated that neither control nor IU arsenic-exposed mice exhibited changes over time (Figure 3A). Similar to total cholesterol values, LDL cholesterol values (Figure 3B) were consistently elevated in the IU arsenic-exposed animals at 4 months $(p=0.0001)$ and 8 months ( $p=0.034$ ), when compared to controls, without a significant change over time. HDL cholesterol values for the IU arsenic-exposed mice were significantly elevated only at the 4 months of age ( $p=0.03)$; however, a trend towards elevated HDL was apparent at weaning age and 8 months of age when compared to controls (Figure $3 \mathrm{C}$ ). Evaluation of triglyceride levels revealed no significant change between IU arsenic-exposed and control mice (Figure 3D). While, a significant decrease was observed in the IU arsenic-exposed group between weaning age and 4 months of age $(p=0.02)$, the change was not present by 8 months of age.

\section{Liver histology}

The detection of increased circulating lipids in the plasma of IU arsenic-exposed mice prompted investigation of livers for pathology. Gross examination of livers from control mice revealed no obvious signs of steatosis, whereas in $70 \%$ of IU arsenic-exposed mouse livers, consistent discoloration indicative of steatosis was observed (4 slides per liver). Histological examination of hematoxylin and eosin staining revealed normal liver architecture in control mice (Figure 4A). In contrast, the livers of IU arsenic-exposed mice exhibited prominent micro and macrovesicular steatosis. Macrovesicular steatosis and hepatocellular ballooning are evident (black arrows) as well as contiguous microvesicular steatosis (white arrows) in the IU arsenic-exposed group (Figure 4C). Livers of control mice showed minor signs of lipid accumulation as detected by Oil Red-O staining (Figure 4B), whereas the livers of IU arsenic-exposed mice had substantially larger lipid droplet accumulation (Figure 4D, gray arrows). Masson's trichrome staining was performed to assess fibrotic changes; however, no overt alterations were observed between livers of control (Figure 5A) and IU arsenic-exposed mice (Figure 5B). Consistent with these observations, liver damage evaluated

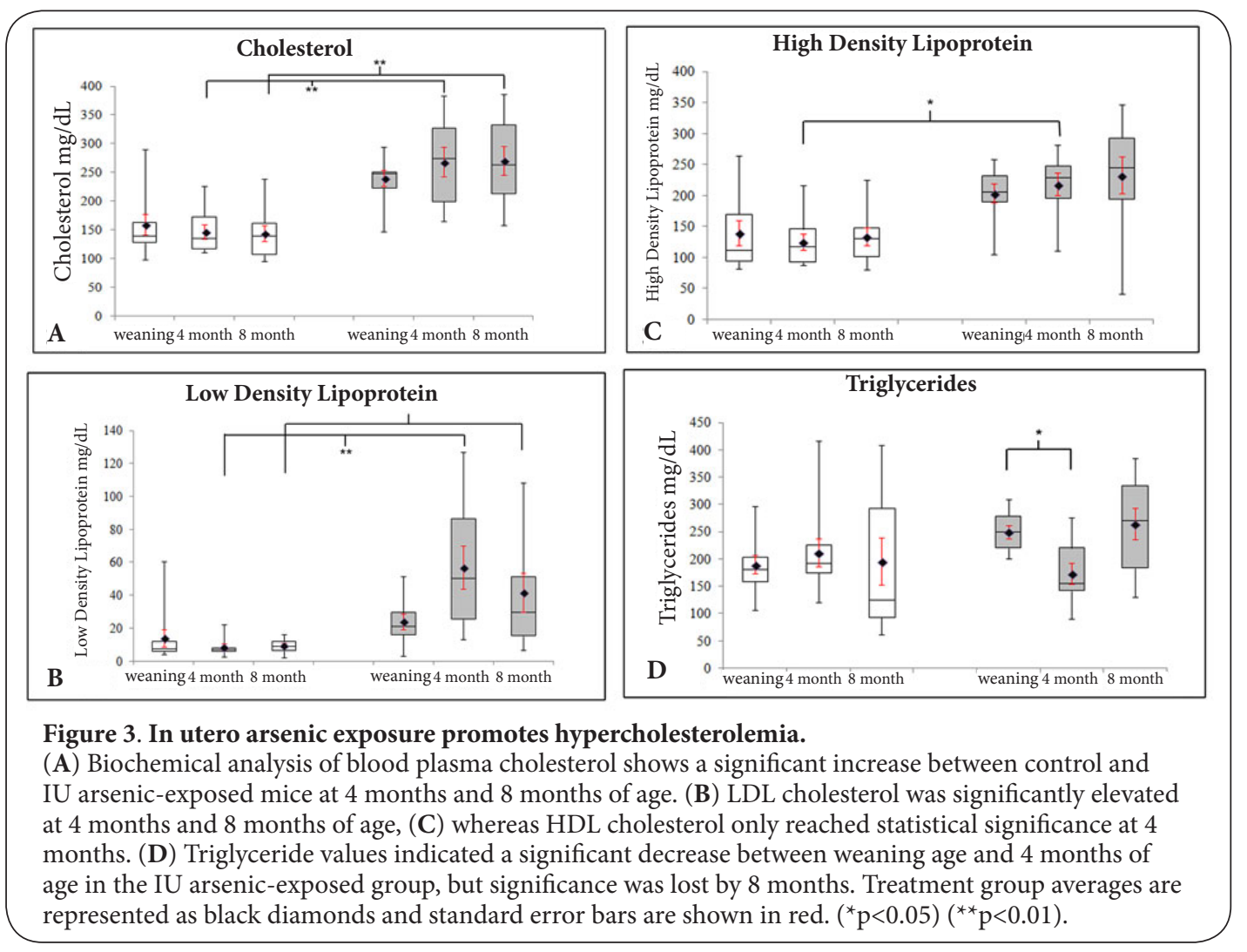

by analysis of terminal circulating plasma ALT, AST, and ALP, demonstrated no significant differences between control and IU arsenic-exposed mice (Figure 5C). Additionally, the
NAFLD activity score (NAS) was used as a semiquantitative scoring system useful for assessing histological features of NAFLD progression. Control animals showed little to no signs 

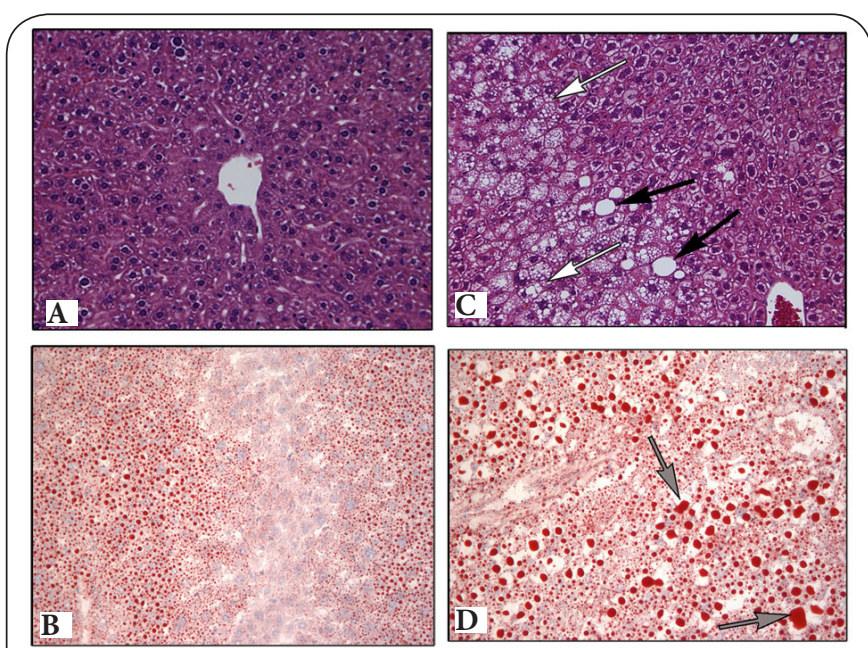

Figure 4. In utero arsenic exposure promotes the development of nonalcoholic fatty liver disease $(\mathrm{A}, \mathrm{B})$ Histological assessment shows normal morphology of control livers, (C,D) whereas IU arsenic-exposed mouse livers. demonstrate major morphological changes, as shown by $\mathrm{H} \& \mathrm{E}$ stain. Macrovesicular steatosis and hepatocellular ballooning are evident (black arrows) as well as contiguous microvesicular steatosis (white arrows) in the IU arsenic-exposed group (compare A to C). (B) Lipid droplet staining by Oil Red-O (B, D) shows minimal traces of lipid accumulation in control livers, (D) whereas IU arsenic exposed mouse livers have a substantial increase in lipid droplet size and accumulation.

of steatosis and no indications of hepatocellular damage. In contrast, livers from IU arsenic-exposed mice showed contiguous microvesicular steatosis (+1)(white arrows), as well as hepatocellular ballooning (+1) (black arrows). Fibrosis, megamitochondria or inflammation were not observed (+0) in IU arsenic-exposed animals, resulting in an overall NAFLD activity score of +2 . This suggests a NAFLD-(not NASH (nonalcoholic steatohepatitis)) state, as defined by a total NAS value of $<3$ [30].

\section{Discussion}

Chronic arsenic exposure has been well studied and evaluated in the context of adult disease; however, little is known about the contribution of fetal arsenic exposure to disease onset and progression. Several studies established a strong association between chronic arsenic exposure and an increased prevalence of hypertension [34,35], atherosclerosis $[36,37]$, and ischemic heart disease-related mortalities $[38,39]$. Importantly, these epidemiological studies have shown that the relationship between cardiovascular disease and arsenic exposure is not only dependent on dose, but also on duration of exposure. Seldom have studies evaluated the contribution of developmental exposures. However, Smith's group [10] provided strong evidence for the association between arsenic exposure through drinking water, and a sustained increased risk in circulatory disease-related mortalities, years after exposure. More importantly, the studies by Smith's group provided some

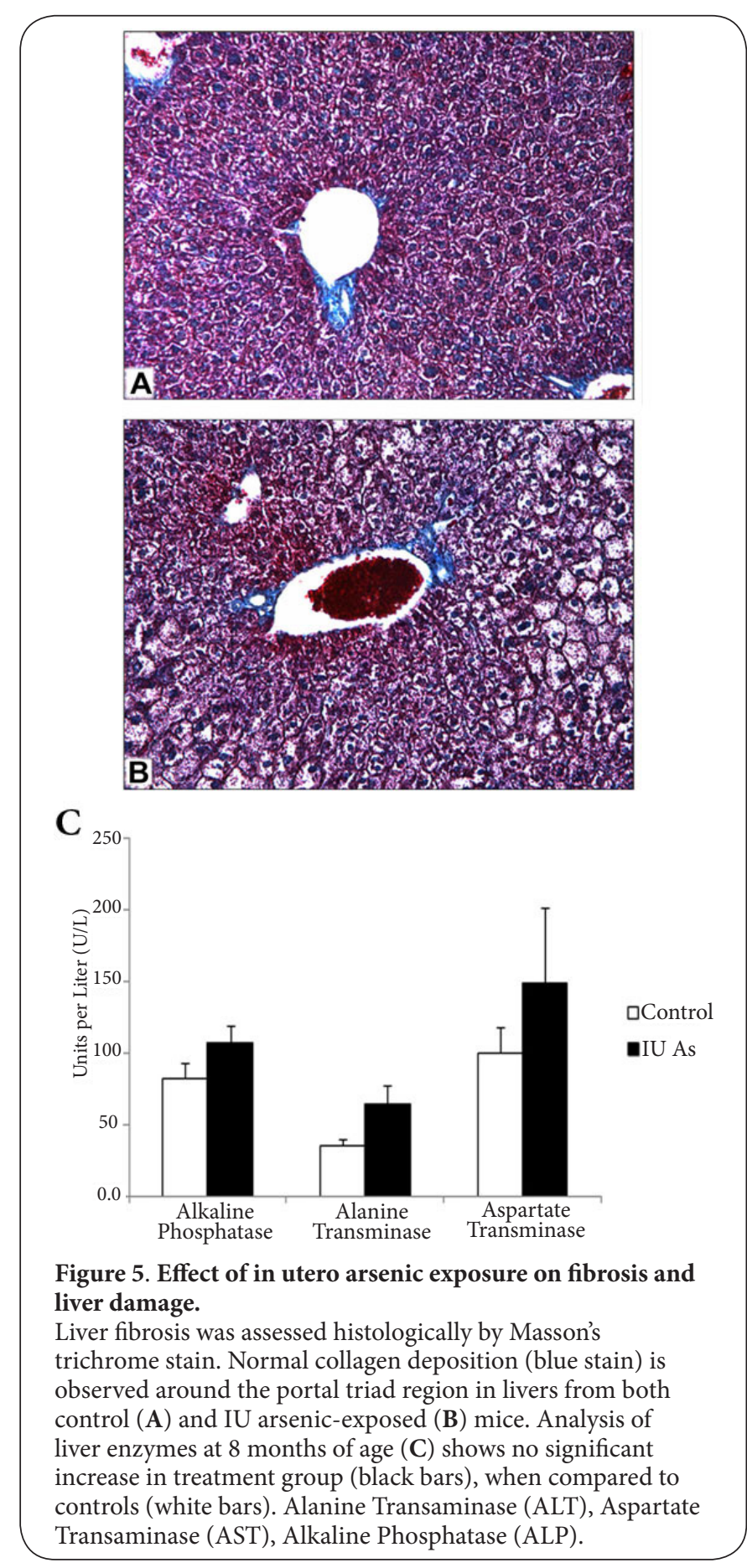

of the first evidence in humans of the detrimental health effects from IU arsenic exposure resulting in an increased incidence of myocardial infarction in adults [10]. Similarly, arsenic exposure has been linked to NAFLD, obesity and diabetes, even though the exact the molecular mechanisms are not fully understood [40]. Although these associations have been shown before, to our knowledge, no reports of fetal arsenic exposure exist showing an association to NAFLD.

Obesity is a key component of metabolic syndrome, and it 
is also an important risk factor for cardiovascular disease; as such, the weight of each mouse was monitored throughout the study. An interesting observation was that the female mice exposed to arsenic IU were significantly underweight during the first two weeks after birth, when compared to their control counterparts. Similarly, Kozul-Horvath et al., showed that female mice that were exposed to $10 \mathrm{ppb}$ arsenic IU, had a delay in weight gain at postnatal day 21 [8]. Our IU arsenicexposed mice showed a full recovery in weight by 4 weeks of age, and no significant changes were observed thereafter. Although a trend towards higher body weights was observed for both males and females, there was no statistical significance when compared to their control counterparts.

The array of biochemical and clinical markers of metabolic syndrome and cardiovascular disease observed in this study are of major significance, considering that exposures to 100 ppb doses are quite prevalent throughout the world [2-5]. The progression of hyperglycemia between weaning age and 4 months of age is similar to what would be expected from the development of insulin resistance in type 2 diabetes mellitus. The most frequent cause of hyperglycemia in diabetes mellitus results from a deficiency in insulin secretion or action. However, insulin levels were not measured successfully in our plasma samples. One of the pitfalls of insulin detection in serum is that the occurrence of hemolysis, and sample freeze-thawing results in substantial degradation and matrix interference during detection $[\mathbf{4 1}, \mathbf{4 2}]$. All of these limitations, compounded by the limited sensitivity of insulin immunoassays, make insulin detection methods particularly challenging. It is also possible that the observed hyperglycemia is linked to the development of NAFLD, and therefore, additional studies are needed to investigate the effects of fetal arsenic exposure on insulin levels. Nevertheless, the observation that glucose levels increased over time in the IU arsenic-exposed mice is consistent with the epidemiological studies associating type 2 diabetes mellitus with arsenic exposure [29,31], as well as with molecular mechanism and animal studies demonstrating that arsenic may impair insulin response and sensitivity $[27,28,43,44]$.

Elevated cholesterol is an important risk factor associated with metabolic syndrome that contributes to its association with reduced cardiovascular health. Specifically, elevation of $\mathrm{LDL}$ cholesterol is a major component causing and influencing atherogenesis and coronary heart disease, and it is the single most important clinical predictor of coronary artery disease [45-48].

A limitation of using a mouse model in this case, is that it provides limited insights to the significance of the observed increase in cholesterol with respect to cardiovascular health in humans, since non-genetically-predisposed mice have very low LDL cholesterol values, and turnover rates are different when compared to humans. Typically, mouse LDL hepatic clearance rates reach $500 \mathrm{ml} / \mathrm{day} / \mathrm{kg}$, which is about 40 -fold greater than human hepatic LDL clearances [49]. Consequently, the steady-state concentration of LDL cholesterol in wild- type mice is approximately $7 \mathrm{mg} / \mathrm{dl}$, whereas in humans this value usually exceeds $100 \mathrm{mg} / \mathrm{dl}$ [50]. Nevertheless, this study demonstrates that a substantial increase in circulating LDL cholesterol was present in mice exposed to arsenic during fetal development, and the ramifications of this observation are likely to have an impact in the context of cardiovascular health, and should be evaluated closely in human populations exposed to arsenic in utero.

Similar to the increase in LDL cholesterol, IU arsenic-exposed mice had elevated HDL values at 4 months. While the underlying mechanisms behind this observation remain unclear, we postulate that this is a reflection of the impaired cholesterol metabolism, and not a beneficial effect of arsenic exposure.

Circulating triglycerides were analyzed in control and IU arsenic-exposed mice. Similar to Srivastava's observations in the ApoE ${ }^{-/}$mouse model [37], a significant decrease in triglycerides was observed in the IU arsenic-exposed group between weaning age and 4 months of age. Interestingly this decrease was not detected by the 8 month time point. Whether these observations are a result of compensatory or adaptation mechanisms remains unclear. Nevertheless, it is believed that LDL cholesterol, rather than triglycerides, is the main contributor to the progression of cardiovascular diseases such as atherosclerosis. Increased levels of non-fasting triglycerides often indicate the presence of an atherogenic state; however, all human cells are able to degrade triglycerides, but not cholesterol. It is, therefore, the LDL cholesterol content that can cause atherosclerosis upon entrance into the arterial intima [51,52]. Additionally, detection of triglycerides and lipid accumulation in the livers of IU arsenic-exposed mice provides strong evidence that early arsenic exposure promotes the onset and progression of NAFLD. In humans, increased risk of cardiovascular disease is associated with NAFLD, as it is often a co-morbidity that develops in metabolic syndrome $[\mathbf{5 3}, \mathbf{5 4}]$. Furthermore, NAFLD is increasingly recognized as the hepatic manifestation of insulin resistance and metabolic syndrome [55]. Importantly, NAFLD is estimated to be prevalent in 20-30\% of the general population in western countries [56], so understanding the underlying causes for the onset and progression of this disease is essential. In this regard, our results are consistent with previous studies showing that arsenic exposure leads to fatty livers in pregnant female mice [8]. Thus, arsenic may be an important toxicant with particular sensitivity to the developing fetus, predisposing mice to NAFLD.

To evaluate plasma biochemistry, mice were in the nonfasted state prior to blood collection. There were two reasons behind this. First, we believe that atherogenesis and cardiovascular disease progression are largely a postprandial phenomenon. Humans spend a larger portion of their lives in the postprandial state, while paradoxically, the vast majority of studies assessing cardiovascular disease risk factors are conducted in a fasted state. Importantly, it has been demonstrated that fasted triglyceride values do not represent an independent risk factor 
Sanchez-Soria et al. Journal of Toxicology and Health 2014,

http://www.hoajonline.com/journals/pdf/2056-3779-1-1.pdf

doi: 10.7243/2056-3779-1-1

for cardiovascular disease, whereas studies in the postprandial state show that triglycerides can be used as a predictor of coronary heart disease [57], myocardial infarction, and ischemic heart disease-related deaths [58-60]. Similarly, in type 2 diabetes mellitus patients, non-fasting blood glucose level has been shown to be a better predictor of cardiovascular events than fasting blood levels $[6 \mathbf{6 1} 6 \mathbf{6 2}]$. Secondly, as mentioned previously, the mice in this study were not genetically predisposed to develop diabetes or atherosclerosis, so we believed that this represented a possibility for false negative results, given enough time in the fasted state.

When designing studies of IU exposure, controlling for variables like gender ratio between treatment groups becomes challenging, since treatment is determined prior to identification of gender of the offspring. By using the mixed effects model, we are able to accommodate the unbalanced data and attempt to control for the gender effect. However, given this gender imbalance between the control and IU arsenic-exposed groups, it becomes a challenging task to tease apart to what extent treatment and gender contribute independently to the observed effects. While our model did reveal a statistically significant treatment effect (independent of gender effect), confirmation of these findings with larger numbers of animals would need to be conducted to better assess the contribution of gender, independent of other variables, to arsenic triggered diseases. Furthermore, it is possible that gender specific pathophysiological differences exist in the onset of metabolic syndrome [63].

\section{Conclusions}

In summary, we demonstrate that fetal exposure to arsenic results in the development of multiple risk factors for the development of metabolic syndrome, which are also significant contributors to cardiovascular-related mortalities. The presence of several components of metabolic syndrome in mice suggests that fetal exposures to arsenic may contribute to dysregulation of regulatory pathways important for glucose and lipid homeostasis. Mechanisms of arsenic-mediated metabolic disruption go beyond the scope of this manuscript, and are discussed in great reviews [26,64-66]; however, preliminary findings from our lab indicate that arsenic may be affecting the function of key enzymes involved in energy metabolism and the tricarboxylic acid (TCA) cycle. Given the pivotal role that the liver plays in glucose and lipid homeostasis, it is likely that disruption of a central bioenergetics pathway such as the TCA cycle could contribute to the effects observed in this study.

The findings presented here are novel and suggest an association between IU arsenic exposure and metabolic syndrome that has not been evaluated before. Collectively, these results suggest that developmental exposure to arsenic is a previously unrecognized contributor to the onset of metabolic syndrome, and likely increases the risk of developing cardiovascular disease; however additional investigation is necessary to understand the implications these findings may have in human health.

\section{List of abbreviations}

ALP: Alkaline Phosphatase

ALT: Alanine Transaminase

AST: Aspartate Transaminase

HDL: High Density Lipoprotein

IACUC: Institutional Animal Care \& Use Committee

IU: In utero

LDL: Low Density Lipoprotein

NADPH: Nicotinamide Adenine Dinucleotide Phosphate

NAFLD: Nonalcoholic Fatty Liver Disease

NAS: NAFLD Activity Scoring

NASH: Nonalcoholic Steatohepatitis

PBS: Phosphate Buffered Solution

ppb: parts per billion

RM-ANOVA: Repeated Measures Analysis of Variance

\section{Competing interests}

The authors declare that they have no competing interests.

\section{Authors' contributions}

\begin{tabular}{|l|c|c|c|c|c|c|}
\hline Authors' contributions & PS & DB & SQ & RNH & NJC & TDC \\
\hline Research concept and design & $\checkmark$ & -- & -- & -- & -- & $\checkmark$ \\
\hline Collection and/or assembly of data & $\checkmark$ & $\checkmark$ & $\checkmark$ & $\checkmark$ & -- & -- \\
\hline Data analysis and interpretation & $\checkmark$ & -- & -- & -- & -- & $\checkmark$ \\
\hline Writing the article & $\checkmark$ & -- & -- & -- & -- & $\checkmark$ \\
\hline Critical revision of the article & $\checkmark$ & $\checkmark$ & -- & $\checkmark$ & $\checkmark$ & $\checkmark$ \\
\hline Final approval of article & $\checkmark$ & $\checkmark$ & $\checkmark$ & $\checkmark$ & $\checkmark$ & $\checkmark$ \\
\hline Statistical analysis & $\checkmark$ & -- & -- & -- & -- & -- \\
\hline
\end{tabular}

\section{Acknowledgement}

The authors thank the University of Arizona Histology Service Lab for assistance with cryo-sectioning, as well as the UC Davis Comparative Pathology Lab for plasma biochemistry analysis. We would like to thank Dr. Dean Billheimer and Isaac Jenkins for assistance with the statistical analyses. P.S.S. would also like to acknowledge T.D. Crew for thoughtful discussions.

\section{Publication history}

Editor: Mihalis Panagiotidis, Heriot Watt University, UK.

Received: 09-Apr-2014 Final Revised: 30-May-2014

Accepted: 06-Jun-2014 Published: 23-Jun-2014

\section{References}

1. National Research Council (US). Subcommittee on Arsenic in Drinking Water. Arsenic in drinking water. National Academies Press. 1999. I Book

2. Chen SL, Dzeng SR, Yang MH, Chiu KH, Shieh GM and Wai CM. Arsenic species in groundwaters of the blackfoot disease area, taiwan. Environ Sci Technol. 1994; 28:877-81. | Article | PubMed

3. Brown KG and Ross GL. Arsenic, drinking water, and health: a position paper of the American Council on Science and Health. Regul Toxicol Pharmacol. 2002; 36:162-74. | Article | PubMed

4. Van Halem D, Bakker S, Amy G and Van Dijk J. Arsenic in drinking water: a worldwide water quality concern for water supply companies. Drinking Water Eng.Sci. 2009; 2:29-34. | Pdf

5. Karagas MR. Arsenic-related mortality in Bangladesh. Lancet. 2010; 376:213-4. | Article | PubMed Abstract | PubMed Full Text

6. Abernathy CO, Liu YP, Longfellow D, Aposhian HV, Beck B, Fowler B, Goyer R, Menzer R, Rossman T, Thompson C and Waalkes M. Arsenic: health effects, mechanisms of actions, and research issues. Environ Health Perspect. 1999; 107:593-7. | Article | PubMed Abstract | PubMed Full $\underline{\text { Text }}$

7. Mandal BK and Suzuki KT. Arsenic round the world: a review. Talanta. 
Sanchez-Soria et al. Journal of Toxicology and Health 2014,

http://www.hoajonline.com/journals/pdf/2056-3779-1-1.pdf

doi: $10.7243 / 2056-3779-1-1$

\section{2; 58:201-35. | Article | PubMed}

8. Kozul-Horvath CD, Zandbergen F, Jackson BP, Enelow RI and Hamilton JW. Effects of low-dose drinking water arsenic on mouse fetal and postnatal growth and development. PLoS One. 2012; 7:e38249. | Article | PubMed Abstract | PubMed Full Text

9. Sanchez-Soria P, Broka D, Monks SL and Camenisch TD. Chronic low-level arsenite exposure through drinking water increases blood pressure and promotes concentric left ventricular hypertrophy in female mice. Toxicol Pathol. 2012; 40:504-12. | Article | PubMed Abstract | PubMed Full Text

10. Yuan Y, Marshall G, Ferreccio C, Steinmaus C, Selvin S, Liaw J, Bates MN and Smith $\mathrm{AH}$. Acute myocardial infarction mortality in comparison with lung and bladder cancer mortality in arsenic-exposed region II of Chile from 1950 to 2000. Am J Epidemiol. 2007; 166:1381-91. | Article | PubMed

11. Bateson P, Barker D, Clutton-Brock T, Deb D, D'Udine B, Foley RA, Gluckman P, Godfrey K, Kirkwood T, Lahr MM, McNamara J, Metcalfe NB, Monaghan P, Spencer HG and Sultan SE. Developmental plasticity and human health. Nature. 2004; 430:419-21. | Article | PubMed

12. Gluckman PD and Hanson MA. The developmental origins of the metabolic syndrome. Trends Endocrinol Metab. 2004; 15:183-7. | Article I PubMed

13. Gluckman PD, Hanson MA, Cooper C and Thornburg KL. Effect of in utero and early-life conditions on adult health and disease. N Engl J Med. 2008; 359:61-73. | Article | PubMed Abstract | PubMed Full Text

14. Barker DJ and Osmond C. Infant mortality, childhood nutrition, and ischaemic heart disease in England and Wales. Lancet. 1986; 1:1077-81. | Article | PubMed

15. Osmond C, Barker DJ, Winter PD, Fall CH and Simmonds SJ. Early growth and death from cardiovascular disease in women. BMJ. 1993; 307:151924. | Article | PubMed Abstract | PubMed Full Text

16. Bhargava SK, Sachdev HS, Fall CH, Osmond C, Lakshmy R, Barker DJ, Biswas SK, Ramji S, Prabhakaran D and Reddy KS. Relation of serial changes in childhood body-mass index to impaired glucose tolerance in young adulthood. N Engl J Med. 2004; 350:865-75. | Article | PubMed Abstract | PubMed Full Text

17. Barker DJ, Osmond C, Forsen TJ, Kajantie E and Eriksson JG. Trajectories of growth among children who have coronary events as adults. $N$ Engl J Med. 2005; 353:1802-9. | Article | PubMed

18. Hovi P, Andersson S, Eriksson JG, Jarvenpaa AL, Strang-Karlsson S, Makitie $\mathrm{O}$ and Kajantie $\mathrm{E}$. Glucose regulation in young adults with very low birth weight. N Engl J Med. 2007; 356:2053-63. | Article | PubMed

19. Wang SL, Chang FH, Liou SH, Wang HJ, Li WF and Hsieh DP. Inorganic arsenic exposure and its relation to metabolic syndrome in an industrial area of Taiwan. Environ Int. 2007; 33:805-11. | Article | PubMed

20. Choi WS, Kim SH and Chung JH. Relationships of hair mineral concentrations with insulin resistance in metabolic syndrome. Biol Trace Elem Res. 2014; 158:323-9. | Article | PubMed

21. Grundy SM, Brewer HB, Jr., Cleeman JI, Smith SC, Jr. and Lenfant C. Definition of metabolic syndrome: Report of the National Heart, Lung, and Blood Institute/American Heart Association conference on scientific issues related to definition. Circulation. 2004; 109:433-8. | Article I PubMed

22. Grundy SM, Cleeman JI, Daniels SR, Donato KA, Eckel RH, Franklin BA, Gordon DJ, Krauss RM, Savage PJ, Smith SC, Jr., Spertus JA and Costa F. Diagnosis and management of the metabolic syndrome: an American Heart Association/National Heart, Lung, and Blood Institute Scientific Statement. Circulation. 2005; 112:2735-52. | Article | PubMed

23. Paschos $P$ and Paletas $K$. Non alcoholic fatty liver disease and metabolic syndrome. Hippokratia. 2009; 13:9-19. | PubMed Abstract | PubMed Full $\underline{\text { Text }}$

24. AlSaraj F, McDermott JH, Cawood T, McAteer S, Ali M, Tormey W, Cockburn BN and Sreenan S. Prevalence of the metabolic syndrome in patients with diabetes mellitus. Ir J Med Sci. 2009; 178:309-13. | Article I PubMed

25. Ervin RB. Prevalence of metabolic syndrome among adults $\mathbf{2 0}$ years of age and over, by sex, age, race and ethnicity, and body mass index:
United States, 2003-2006. Natl Health Stat Report. 2009; 1-7. I PubMed

26. Navas-Acien A, Silbergeld EK, Streeter RA, Clark JM, Burke TA and Guallar E. Arsenic exposure and type 2 diabetes: a systematic review of the experimental and epidemiological evidence. Environ Health Perspect. 2006; 114:641-8. | Article | PubMed Abstract | PubMed Full $\underline{\text { Text }}$

27. Paul DS, Harmon AW, Devesa V, Thomas DJ and Styblo M. Molecular mechanisms of the diabetogenic effects of arsenic: inhibition of insulin signaling by arsenite and methylarsonous acid. Environ Health Perspect. 2007; 115:734-42. | Article | PubMed Abstract | PubMed Full Text

28. Paul DS, Hernandez-Zavala A, Walton FS, Adair BM, Dedina J, Matousek $T$ and Styblo M. Examination of the effects of arsenic on glucose homeostasis in cell culture and animal studies: development of a mouse model for arsenic-induced diabetes. Toxicol Appl Pharmacol. 2007; 222:305-14. | Article | PubMed Abstract | PubMed Full Text

29. Xue P, Hou Y, Zhang Q, Woods CG, Yarborough K, Liu H, Sun G, Andersen $\mathrm{ME}$ and $\mathrm{Pi}$ J. Prolonged inorganic arsenite exposure suppresses insulinstimulated AKT S473 phosphorylation and glucose uptake in 3T3-L1 adipocytes: involvement of the adaptive antioxidant response. Biochem Biophys Res Commun. 2011; 407:360-5. | Article | PubMed Abstract | PubMed Full Text

30. Kleiner DE, Brunt EM, Van Natta M, Behling C, Contos MJ, Cummings OW, Ferrell LD, Liu YC, Torbenson MS, Unalp-Arida A, Yeh M, McCullough AJ and Sanyal AJ. Design and validation of a histological scoring system for nonalcoholic fatty liver disease. Hepatology. 2005; 41:1313-21. | Article I PubMed

31. Lai MS, Hsueh YM, Chen CJ, Shyu MP, Chen SY, Kuo TL, Wu MM and Tai TY. Ingested inorganic arsenic and prevalence of diabetes mellitus. Am J Epidemiol. 1994; 139:484-92. | Article | PubMed

32. Coronado-Gonzalez JA, Del Razo LM, Garcia-Vargas G, Sanmiguel-Salazar $\mathrm{F}$ and Escobedo-de la Pena J. Inorganic arsenic exposure and type 2 diabetes mellitus in Mexico. Environ Res. 2007; 104:383-9. | Article | PubMed

33. Navas-Acien A, Silbergeld EK, Pastor-Barriuso R and Guallar E. Arsenic exposure and prevalence of type 2 diabetes in US adults. JAMA. 2008; 300:814-22. | Article | PubMed

34. Chen CJ, Hsueh YM, Lai MS, Shyu MP, Chen SY, Wu MM, Kuo TL and Tai TY. Increased prevalence of hypertension and long-term arsenic exposure. Hypertension. 1995; 25:53-60. | Article I PubMed

35. Rahman M, Tondel M, Ahmad SA, Chowdhury IA, Faruquee MH and Axelson O. Hypertension and arsenic exposure in Bangladesh. Hypertension. 1999; 33:74-8. | Article | PubMed

36. Wang CH, Jeng JS, Yip PK, Chen CL, Hsu LI, Hsueh YM, Chiou HY, Wu MM and Chen $\mathrm{CJ}$. Biological gradient between long-term arsenic exposure and carotid atherosclerosis. Circulation. 2002; 105:1804-9. | Article | PubMed

37. Srivastava S, D'Souza SE, Sen U and States JC. In utero arsenic exposure induces early onset of atherosclerosis in ApoE-/- mice. Reprod Toxicol. 2007; 23:449-56. | Article | PubMed Abstract | PubMed Full Text

38. Chen CJ, Chiou HY, Chiang MH, Lin LJ and Tai TY. Dose-response relationship between ischemic heart disease mortality and long-term arsenic exposure. Arterioscler Thromb Vasc Biol. 1996; 16:504-10. | Article I PubMed

39. Chen Y, Graziano JH, Parvez F, Liu M, Slavkovich V, Kalra T, Argos M, Islam T, Ahmed A, Rakibuz-Zaman M, Hasan R, Sarwar G, Levy D, van Geen A and Ahsan $\mathrm{H}$. Arsenic exposure from drinking water and mortality from cardiovascular disease in Bangladesh: prospective cohort study. BMJ. 2011; 342:d2431. | Article | PubMed Abstract | PubMed Full Text

40. Arciello M, Gori M, Maggio R, Barbaro B, Tarocchi M, Galli A and Balsano C. Environmental pollution: a tangible risk for NAFLD pathogenesis. Int J Mol Sci. 2013; 14:22052-66. | Article | PubMed Abstract | PubMed Full Text

41. Sapin R. Insulin immunoassays: fast approaching $\mathbf{5 0}$ years of existence and still calling for standardization. Clin Chem. 2007; 53:810-2. | Article I PubMed

42. Reimers TJ, McCann JP, Cowan RG and Concannon PW. Effects of storage, 
Sanchez-Soria et al. Journal of Toxicology and Health 2014,

hemolysis, and freezing and thawing on concentrations of thyroxine, cortisol, and insulin in blood samples. Proc Soc Exp Biol Med. 1982; 170:509-16. | Article | PubMed

43. Walton FS, Harmon AW, Paul DS, Drobna Z, Patel YM and Styblo M. Inhibition of insulin-dependent glucose uptake by trivalent arsenicals: possible mechanism of arsenic-induced diabetes. Toxicol Appl Pharmacol. 2004; 198:424-33. | Article | PubMed

44. Paul DS, Walton FS, Saunders RJ and Styblo M. Characterization of the impaired glucose homeostasis produced in C57BL/6 mice by chronic exposure to arsenic and high-fat diet. Environ Health Perspect. 2011; 119:1104-9. | Article | PubMed Abstract | PubMed Full Text

45. Rifai N, Warnick GR, McNamara JR, Belcher JD, Grinstead GF and Frantz ID, Jr. Measurement of low-density-lipoprotein cholesterol in serum: a status report. Clin Chem. 1992; 38:150-60. | Article | PubMed

46. Naito H. K. 18th Annual Symposium, National Academy of Clinical Biochemistry Atherogenesis: Current Topics on Etiology and Risk Factors. Clin Chem. 1995; 41:132-3. | Pdf

47. Bachorik, P. S. Measurement of low-density-lipoprotein cholesterol. (2000). Handbook of Lipoprotein testing.2nd ed.Washington, DC: AACC Press 12, 245-63.

48. National Institutes of Health. Executive Summary of the Third Report of the National Cholesterol Education Program (NCEP) Expert Panel on Detection, Evaluation, and Treatment of High Blood Cholesterol in Adults (Adult Treatment Panel III). JAMA. 2001; 285:2486-2497. | Article

49. Dietschy JM, Turley SD and Spady DK. Role of liver in the maintenance of cholesterol and low density lipoprotein homeostasis in different animal species, including humans. J Lipid Res. 1993; 34:1637-59. | Article | PubMed

50. Dietschy JM and Turley SD. Control of cholesterol turnover in the mouse. J Biol Chem. 2002; 277:3801-4. | Article | PubMed

51. Zilversmit DB. Atherogenesis: a postprandial phenomenon. Circulation. 1979; 60:473-85. | Article | PubMed

52. Kolovou GD, Anagnostopoulou KK, Daskalopoulou SS, Mikhailidis DP and Cokkinos DV. Clinical relevance of postprandial lipaemia. Curr Med Chem. 2005; 12:1931-45. | Article | PubMed

53. Ekstedt M, Franzen LE, Mathiesen UL, Thorelius L, Holmqvist M, Bodemar $G$ and Kechagias S. Long-term follow-up of patients with NAFLD and elevated liver enzymes. Hepatology. 2006; 44:865-73. | Article | PubMed

54. Paschos $P$ and Paletas K. Non alcoholic fatty liver disease and metabolic syndrome. Hippokratia. 2009; 13:9-19. | PubMed Abstract | PubMed Full Text

55. Marchesini G, Brizi M, Bianchi G, Tomassetti S, Bugianesi E, Lenzi M, McCullough AJ, Natale S, Forlani G and Melchionda N. Nonalcoholic fatty liver disease: a feature of the metabolic syndrome. Diabetes. 2001; 50:1844-50. | Article | PubMed

56. Bedogni G, Miglioli L, Masutti F, Tiribelli C, Marchesini G and Bellentani S. Prevalence of and risk factors for nonalcoholic fatty liver disease: the Dionysos nutrition and liver study. Hepatology. 2005; 42:44-52. | Article I PubMed

57. Eberly LE, Stamler J and Neaton JD. Relation of triglyceride levels, fasting and nonfasting, to fatal and nonfatal coronary heart disease. Arch Intern Med. 2003; 163:1077-83. | Article | PubMed

58. Iso H, Naito Y, Sato S, Kitamura A, Okamura T, Sankai T, Shimamoto T, lida $\mathrm{M}$ and Komachi $\mathrm{Y}$. Serum triglycerides and risk of coronary heart disease among Japanese men and women. Am J Epidemiol. 2001; 153:490-9. | Article | PubMed

59. Bansal S, Buring JE, Rifai N, Mora S, Sacks FM and Ridker PM. Fasting compared with nonfasting triglycerides and risk of cardiovascular events in women. JAMA. 2007; 298:309-16. | Article | PubMed

60. Nordestgaard BG, Benn M, Schnohr P and Tybjaerg-Hansen A. Nonfasting triglycerides and risk of myocardial infarction, ischemic heart disease, and death in men and women. JAMA. 2007; 298:299-308. | Article | PubMed

61. Wannamethee SG, Perry IJ and Shaper AG. Nonfasting serum glucose and insulin concentrations and the risk of stroke. Stroke. 1999; 30:1780-
6. | Article | PubMed

62. Cavalot F, Petrelli A, Traversa M, Bonomo K, Fiora E, Conti M, Anfossi $\mathrm{G}$, Costa $\mathrm{G}$ and Trovati M. Postprandial blood glucose is a stronger predictor of cardiovascular events than fasting blood glucose in type 2 diabetes mellitus, particularly in women: lessons from the San Luigi Gonzaga Diabetes Study. J Clin Endocrinol Metab. 2006; 91:813-9. | Article | PubMed

63. Regitz-Zagrosek V, Lehmkuhl E and Weickert MO. Gender differences in the metabolic syndrome and their role for cardiovascular disease. Clin Res Cardiol. 2006; 95:136-47. | Article | PubMed

64. Druwe IL and Vaillancourt RR. Influence of arsenate and arsenite on signal transduction pathways: an update. Arch Toxicol. 2010; 84:585-96. | Article | PubMed Abstract | PubMed Full Text

65. Paul DS, Devesa V, Hernandez-Zavala A, Adair BM, Walton FS, Drobna Z, Thomas DJ and Styblo M. Environmental arsenic as a disruptor of insulin signaling. Met lons Biol Med. 2008; 10:1-7. | PubMed Abstract | PubMed Full Text

66. Tseng $\mathrm{CH}$. The potential biological mechanisms of arsenic-induced diabetes mellitus. Toxicol Appl Pharmacol. 2004; 197:67-83. | Article | PubMed

\section{Citation:}

Sanchez-Soria P, Broka D, Quach S, Hardwick RN, Cherrington NJ and Camenisch TD. Fetal exposure to arsenic results in hyperglycemia, hypercholesterolemia, and nonalcoholic fatty liver disease in adult mice. J Toxicol Health. 2014; 1:1. http://dx.doi.org/10.7243/2056-3779-1-1 